www.nature.com/pj

\title{
Tuning of solubility and gelation ability of oligomeric electrolyte by anion exchange
}

\author{
Nagatoshi Koumura $^{1}$, Hajime Matsumoto ${ }^{2}$, Hajime Kawanami ${ }^{3}$, Nobuyuki Tamaoki ${ }^{4,5}$ and Masaru Yoshida ${ }^{4}$ \\ To tune the miscibility of the gel-forming oligomeric electrolyte, we examined anion exchange reactions using appropriate \\ ammonium or alkali-metal salts. Nine oligomeric electrolytes with different anions were obtained in high yields by the reactions. \\ The solubility of these oligomeric electrolytes in organic solvents was carefully tested. Although the starting material with \\ chloride as a counter anion was not soluble in any organic solvents, excellent miscibility and gelation ability of the oligomeric \\ electrolytes with different anions were consequently observed with dipolar protophilic and aprotic solvents such as $N, N$ - \\ dimethylformamide, dimethylsulfoxide and $\mathbf{N}, \mathbf{N}$-dimethylacetamide. Furthermore, ionogels based on aliphatic ionic liquids were \\ readily formed using the oligomer with bis(trifluoromethanesulfonyl)amide anion at a $40 \mathrm{gl}^{-1}$ concentration. It is remarkable that \\ the ionic conductivity of the above-mentioned ionogels is almost identical to that of neat ionic liquids, despite the significant \\ increase in the apparent viscosity. This study shows a novel and convenient approach to gelators for multiple solvents. \\ Polymer Journal (2010) 42, 759-765; doi:10.1038/pj.2010.65; published online 4 August 2010
}

Keywords: anion exchange; ionic conductivity; physical gels

\section{INTRODUCTION}

The gel is a typical soft matter consisting of an excess of adequate liquid (for example, water or organic solvent) and a relatively small amount of gel-forming compounds. The material often shows both quasi-liquid and quasi-solid natures; thus, many potential applications have been pointed out. ${ }^{1-3}$ Regarding the physical gels, their main feature is a reversible thermal-phase transition between gel and sol states, reflecting the driving force of the gelation based on weak interactions such as hydrogen bonding, $\pi-\pi$ stacking, van der Waals forces, charge transfer interactions and electrostatic forces among the gelator molecules. $^{4-7}$

Although the gel-forming materials based on natural compounds (for example, agar, gelatin) are commercially and inexpensively available in large amounts, they cannot be used for organic solvents because of poor solubility. Difficulty in chemical modification was also observed for such common gel-forming materials. On this account, synthetic gelators promise to improve on the properties of natural gelators by chemical modification of their molecular structure. For instance, when functional groups able to respond to external stimuli are introduced into artificial gelators, the gel-sol transition can be induced by light, ${ }^{8-11}$ pH change ${ }^{12}$ or chemical triggers. ${ }^{13,14}$ Despite such an advantage of the artificial functional gels, large-scale production of synthetic gelators is often limited because of multistep syntheses and tedious purifications.

Solvents also control the gel properties. Gels are generally classified into hydrogels and organogels on the basis of the used solvents, that is, water and organic solvents. Recently, ionic liquids have attracted a great deal of attention as a different type of solvent because of their distinctive properties, including chemical and thermal stability, nonvolatility, lower flammability and high ionic conductivity. ${ }^{15-18}$ Owing to these significant characteristics, there has been extensive research on ionic liquids to clarify their fundamental properties and plausible applications. Several low-molecular-weight ${ }^{19-21}$ or polymeric ${ }^{22,23}$ gelators have been developed for ionic liquids to form ionogels, and the applications of ionogel electrolytes for dye-sensitized solar cells showing long-time stability have been reported. ${ }^{24-27}$

Although there have been reports of amphiphilic gelators for multiple solvents, they are still limited in number. ${ }^{28-30}$ Recently, we reported a new oligomeric physical gelator, poly[pyridinium-1,4diyl-iminocarbonyl-1,4-phenylene-methylene chloride] $\mathbf{1} \cdot \mathbf{C l}$, having pyridinium and amide moieties in its main chain (Scheme 1). ${ }^{31}$ The novel oligomeric gelator 1.Cl was synthesized by a one-pot synthesis involving condensation and subsequent intermolecular quaternization reaction. The ionic gelator $\mathbf{1}$. Cl showed many unique physical properties, especially rheological behavior, showing self-healing after mechanical collapse. ${ }^{31-33}$ In our previous report, we have preliminarily shown that the solubility and gelation ability of the oligomeric electrolyte can be tuned by an anion exchange reaction with fluorinated anions such as hexafluorophosphate $\left(\mathrm{PF}_{6}\right)$ or bis(trifluoromethanesulfonyl)amide (TFSA). ${ }^{31}$ Although the initial oligomeric electrolyte $\mathbf{1} \cdot \mathbf{C l}$ was soluble only in hot water, the products of the

${ }^{1}$ Photonics Research Institute, National Institute of Advanced Industrial Science and Technology (AIST), Tsukuba, Ibaraki, Japan; ${ }^{2}$ Research Institute for Ubiquitous Energy Devices, AIST, Ikeda, Osaka, Japan; ${ }^{3}$ Research Center for Compact Chemical System, AIST, Sendai, Miyagi, Japan and ${ }^{4}$ Nanosystem Research Institute, AIST, Tsukuba, Ibaraki, Japan

${ }^{5}$ Current address: Research Institute for Electronic Science, Hokkaido University, Sapporo, Hokkaido, Japan.

Correspondence: Dr M Yoshida, Nanosystem Research Institute, AIST, 1-1-1 Higashi, Tsukuba, Ibaraki 305-8565, Japan.

E-mail: masaru.yoshida@aist.go.jp

Received 10 February 2010; revised 16 June 2010; accepted 18 June 2010; published online 4 August 2010 


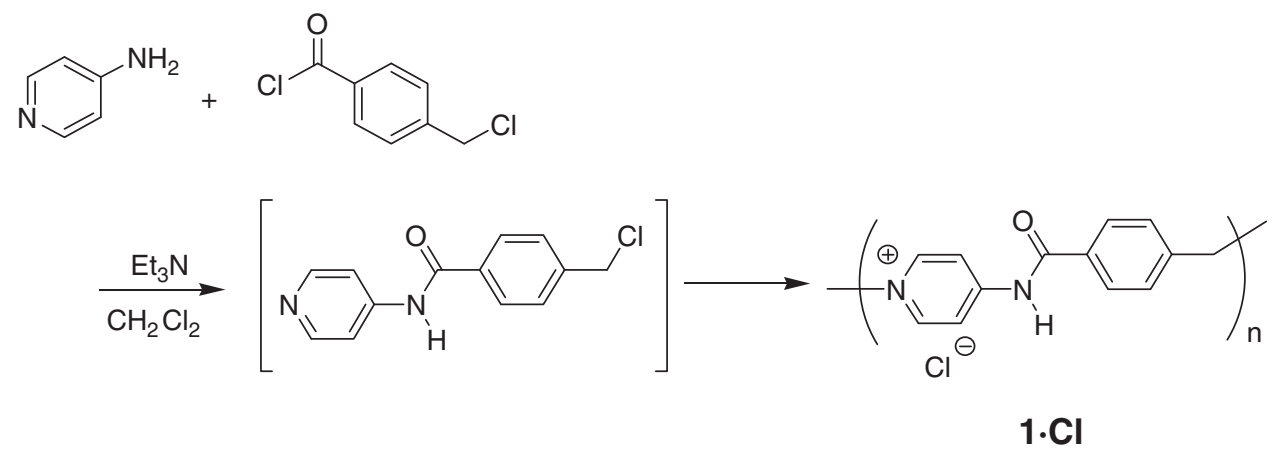

Scheme 1 Synthesis of oligomeric electrolyte $\mathbf{1} \cdot \mathbf{C l}$.

anion exchange reactions were eventually insoluble in water but readily soluble in polar organic solvents. The gelation ability of oligomeric electrolytes $\mathbf{1} \cdot \mathbf{P F}_{\mathbf{6}}$ and $\mathbf{1} \cdot$ TFSA was also briefly shown for several organic solvents and ionic liquids. The results prompted us to further research multisolvent gelators on the basis of chemical tuning by anion exchange using different types of salts. Herein, we report a number of oligomeric electrolytes with other anions, prepared from $\mathbf{1 . C l}$ as a structural scaffold, to prove the usefulness of the anion exchange method. The miscibility and gelation property of the oligomeric electrolytes for several organic solvents and ionic liquids are also described.

\section{EXPERIMENTAL PROCEDURE}

\section{General procedure}

${ }^{1} \mathrm{H}$ and ${ }^{13} \mathrm{C}$ nuclear magnetic resonance (NMR) spectra were recorded on a Bruker Avance-400 (Bruker, Karlsruhe, Germany) $\left({ }^{1} \mathrm{H}: 400 \mathrm{MHz},{ }^{13} \mathrm{C}\right.$ : $100 \mathrm{MHz}$ ). Chemical shifts are denoted in $\delta$-units (p.p.m.) relative to DMSO- $d_{6} \cdot{ }^{19} \mathrm{~F}$ NMR was recorded on a JEOL ECA300 (JEOL, Tokyo, Japan) $\left({ }^{19} \mathrm{~F}: 300 \mathrm{MHz}\right)$ with $\mathrm{CFCl}_{3}$ as an internal standard. The solvents were distilled and dried, if necessary, by standard methods. The reagents, including ionic liquids, were purchased from Aldrich (St Louis, MO, USA), Wako (Tokyo, Japan), Kanto Chemical (Tokyo, Japan), TCI (Tokyo, Japan) and Merck (Darmstadt, Germany). Field-emission scanning electron microscope images were obtained using a Topcon DS-720 (Topcon, Tokyo, Japan). Elemental analyses (only for nonfluorinated derivatives to avoid the generation of hydrogen fluoride) were performed by a CE Instruments EA 1110 automatic elemental analyzer (CE Instruments, Wigan, UK). Because of difficulty in completely drying oligomeric electrolyte samples even in vacuo, the calculated numbers at the elemental analysis have accounted for the hydration water. Sizeexclusion chromatography was conducted on a Shimadzu system (Shimadzu, Kyoto, Japan), comprising an LC-10ADvp pump unit, an SPD-10Avp UV detector $(\lambda=280 \mathrm{~nm})$, a CTO-10Avp column oven and an SCL-10Avp controller, on the Asahipak column (GF-310 HQ (Shodex, Tokyo, Japan), polyvinyl alcohol gel, upper $M_{\mathrm{w}}$ limit: $40000 \mathrm{kDa}$ ) in dimethylformamide eluent containing 5 or $30 \mathrm{~mm}$ of lithium bis(trifluoromethanesulfonyl)imide at $40^{\circ} \mathrm{C}$. Thermal gravimetric analysis (TGA) was performed on a thermal analysis system (Seiko Instruments, Chiba, Japan, TG/DTA 6200) by placing an average sample weight of $3 \mathrm{mg}$ in a platinum pan and heating at $10^{\circ} \mathrm{Cmin}^{-1}$ under a flow of nitrogen.

\section{Anion exchange reaction}

The oligomer $\mathbf{1} \cdot \mathrm{Cl}\left(M_{\mathrm{w}}=2.80, \mathrm{PDI}=1.66\right.$, polystyrene standard $)$ was prepared in a manner similar to that described in the previous report. ${ }^{31}$ To a solution of oligomer $\mathbf{1} \cdot \mathbf{C l}(1 \mathrm{eq})$ in hot water was added an aqueous solution of an excess amount (5-20 eq) of appropriate salt. The reaction mixture was then refluxed for $30 \mathrm{~min}$. After cooling to room temperature, precipitates were formed. The product was filtered off, washed with water and dried under vacuum to obtain the corresponding oligomer with the exchanged anion in over $90 \%$ yield. Using $\mathbf{1} \cdot \mathrm{Cl}(292 \mathrm{mg})$ and ammonium tetrafluoroborate $\left(\mathrm{NH}_{4} \mathrm{BF}_{4}, 6.20 \mathrm{~g}\right)$ as starting materials, $\mathbf{1} \cdot \mathbf{B F}_{4}$ was obtained as a white powder $(343 \mathrm{mg}, 97 \%) ;{ }^{1} \mathrm{H}$ NMR $\left(400 \mathrm{MHz}, \mathrm{DMSO}-d_{6}\right) \delta 11.66(\mathrm{NH}, 1 \mathrm{H}), 8.96(2 \mathrm{H}), 8.35(2 \mathrm{H}), 8.08(2 \mathrm{H}), 7.68$ $(2 \mathrm{H}), 5.83\left(\mathrm{CH}_{2}, 2 \mathrm{H}\right),{ }^{13} \mathrm{C}$ NMR $\left(100 \mathrm{MHz}\right.$, DMSO- $\left.d_{6}\right) \delta 167.0,153.0,145.7$, $139.8,133.7,129.4,129.0,116.5,61.5 .{ }^{19} \mathrm{~F}$ NMR $\left(300 \mathrm{MHz}, \mathrm{DMSO}-d_{6}\right) \delta$ $-147.66\left({ }^{10} \mathrm{~B}-\mathrm{F}\right),-147.72\left({ }^{11} \mathrm{~B}-\mathrm{F}\right)$. Using $\mathbf{1} \cdot \mathrm{Cl}(860 \mathrm{mg})$ and ammonium hexafluorophosphate $\left(\mathrm{NH}_{4} \mathrm{PF}_{6}\right)$ as starting materials, $\mathbf{1} \cdot \mathrm{PF}_{\mathbf{6}}$ was obtained as a white powder $(1.24 \mathrm{~g},>99 \%) ;{ }^{1} \mathrm{H}$ NMR $\left(400 \mathrm{MHz}, \mathrm{DMSO}-d_{6}\right) \delta 11.70(\mathrm{NH}$, $1 \mathrm{H}), 8.96(2 \mathrm{H}), 8.35(2 \mathrm{H}), 8.08(2 \mathrm{H}), 7.67(2 \mathrm{H}), 5.84\left(\mathrm{CH}_{2}, 2 \mathrm{H}\right),{ }^{13} \mathrm{C} \mathrm{NMR}$ $\left(100 \mathrm{MHz}, \mathrm{DMSO}-d_{6}\right) \delta 167.0,153.0,145.7,139.8,133.7,129.5,128.9,116.5$, 61.5. ${ }^{19} \mathrm{~F}$ NMR $\left(300 \mathrm{MHz}\right.$, DMSO- $\left.d_{6}\right) \delta-69.6\left(\mathrm{~J}_{\mathrm{P}-\mathrm{F}}=757 \mathrm{~Hz}\right)$. Using $\mathbf{1} \cdot \mathbf{C l}$ $(277 \mathrm{mg})$ and lithium bis(trifluoromethanesulfonyl)amide (LiTFSA) as starting materials, 1.TFSA was obtained as a white powder $(343 \mathrm{mg}, 97 \%)$; ${ }^{1} \mathrm{H}$ NMR $\left(400 \mathrm{MHz}\right.$, DMSO- $\left.d_{6}\right) \delta 11.73(\mathrm{NH}, 1 \mathrm{H}), 8.96(2 \mathrm{H}), 8.35(2 \mathrm{H}), 8.08(2 \mathrm{H}), 7.67$ $(2 \mathrm{H}), 5.84\left(\mathrm{CH}_{2}, 2 \mathrm{H}\right),{ }^{13} \mathrm{C}$ NMR $\left(100 \mathrm{MHz}\right.$, DMSO- $\left.d_{6}\right) \delta 167.0,153.1,145.6$, $139.8,133.7,129.4,128.9,121.3,118.1,116.5,61.4 .{ }^{19} \mathrm{~F}$ NMR $(300 \mathrm{MHz}$, DMSO- $\left.d_{6}\right) \delta-78.3$. Using $\mathbf{1} \cdot \mathbf{C l}(106 \mathrm{mg})$ and sodium tetraphenylborate $\left(\mathrm{NaBPh}_{4}\right)$ as starting materials, $\mathbf{1} \cdot \mathbf{B P h}$ was obtained as a white powder (215 mg, 94\%); ${ }^{1} \mathrm{H}$ NMR (400 MHz, DMSO- $\left.d_{6}\right) \delta 11.72(\mathrm{NH}, 1 \mathrm{H}), 8.83$ $(2 \mathrm{H}), 8.34(2 \mathrm{H}), 8.10(2 \mathrm{H}), 7.64(2 \mathrm{H}), 7.25(8 \mathrm{H}), 6.96(8 \mathrm{H}), 6.81(4 \mathrm{H}), 5.73$ $\left(\mathrm{CH}_{2}, \quad 2 \mathrm{H}\right),{ }^{13} \mathrm{C} \quad \mathrm{NMR} \quad\left(100 \mathrm{MHz}, \quad\right.$ DMSO- $\left.d_{6}\right) \quad \delta \quad 167.0, \quad 163.6 \quad(\mathrm{q}$, $\left.{ }^{1} \mathrm{~J}_{\mathrm{C}-\mathrm{B}}=49.3 \mathrm{~Hz}\right), 153.0,145.5,139.7,135.8,133.7,129.4,128.8,125.5 \quad(\mathrm{q}$, $\left.{ }^{2} \mathrm{~J}_{\mathrm{C}-\mathrm{B}}=2.6 \mathrm{~Hz}\right), 121.8,116.4$, 61.4. Anal calcd for $\left(\mathrm{C}_{37} \mathrm{H}_{31} \mathrm{BN}_{2} \mathrm{O}\left(\mathrm{H}_{2} \mathrm{O}\right)\right)_{\mathrm{n}}: \mathrm{C}$, 81.02; H, 6.06; N, 5.11. Found: C, 80.98; H, 5.91; N, 5.00. Using 1.Cl (150 mg) and ammonium iodide $\left(\mathrm{NH}_{4} \mathrm{I}\right)$ as starting materials, $\mathbf{1} \cdot \mathbf{I}$ was obtained as a yellow powder (192 mg, 93\%); ${ }^{1} \mathrm{H}$ NMR ( $400 \mathrm{MHz}$, DMSO- $d_{6}$, at $\left.373 \mathrm{~K}\right) \delta 9.02$ $(2 \mathrm{H}), 8.39(2 \mathrm{H}), 8.11(2 \mathrm{H}), 7.71(2 \mathrm{H}), 5.89\left(\mathrm{CH}_{2}, 2 \mathrm{H}\right),{ }^{13} \mathrm{C} \mathrm{NMR}(100 \mathrm{MHz}$, DMSO- $d_{6}$, at $\left.373 \mathrm{~K}\right) \delta 166.2,152.5,144.8,138.6,133.1,128.7,128.4,115.9$, 61.0. Anal calcd for $\left(\mathrm{C}_{13} \mathrm{H}_{11} \mathrm{~N}_{2} \mathrm{IO}\left(\mathrm{H}_{2} \mathrm{O}\right)\right)_{\mathrm{n}}$ : C, 43.84; $\mathrm{H}, 3.68 ; \mathrm{N}, 7.87$. Found: $\mathrm{C}$, $43.52 ; \mathrm{H}, 3.80 ; \mathrm{N}, 7.49$. Using $\mathbf{1} \cdot \mathrm{Cl}(257 \mathrm{mg})$ and sodium thiocyanate as starting materials, $\mathbf{1} \cdot \mathbf{S C N}$ was obtained as a white powder $(268 \mathrm{mg}, 95 \%) ;{ }^{1} \mathrm{H}$ NMR $\left(400 \mathrm{MHz}, \mathrm{DMSO}-d_{6}\right.$, at $\left.353 \mathrm{~K}\right) \delta 11.51(\mathrm{NH}, 1 \mathrm{H}), 8.95(2 \mathrm{H}), 8.35(2 \mathrm{H}), 8.09$ (2H), $7.69(2 \mathrm{H}), 5.86\left(\mathrm{CH}_{2}, 2 \mathrm{H}\right),{ }^{13} \mathrm{C}$ NMR $\left(100 \mathrm{MHz}\right.$, DMSO- $d_{6}$, at $\left.353 \mathrm{~K}\right) \delta$ $166.4,152.7,145.1,138.9,133.3,128.8,128.5,116.1,61.3$. Anal calcd for $\left(\mathrm{C}_{14} \mathrm{H}_{11} \mathrm{~N}_{3} \mathrm{OS}\left(\mathrm{H}_{2} \mathrm{O}\right)_{0.7}\right)_{\mathrm{n}}$ : C, 59.64; H, 4.43; N, 14.90; S, 11.37. Found: C, 59.99; $\mathrm{H}, 4.46 ; \mathrm{N}, 15.01 ; \mathrm{S}, 10.57$. Using $\mathbf{1} \cdot \mathbf{C l}(321 \mathrm{mg})$ and sodium dicyanoamide as starting materials, 1·DCA was obtained as a white powder $(326 \mathrm{mg}, 90 \%) ;{ }^{1} \mathrm{H}$ NMR $\left(400 \mathrm{MHz}\right.$, DMSO- $\left.d_{6}\right) \delta 11.67(\mathrm{NH}, 1 \mathrm{H}), 8.96(2 \mathrm{H}), 8.34(2 \mathrm{H}), 8.08$ $(2 \mathrm{H}), 7.67(2 \mathrm{H}), 5.84\left(\mathrm{CH}_{2}, 2 \mathrm{H}\right),{ }^{13} \mathrm{C}$ NMR $\left(100 \mathrm{MHz}, \mathrm{DMSO}-d_{6}\right) \delta 167.0$, $153.0,145.6,139.8,133.7,129.4,128.9,119.3,116.4,61.4$. Anal calcd for $\left(\mathrm{C}_{15} \mathrm{H}_{11} \mathrm{~N}_{5} \mathrm{O}\left(\mathrm{H}_{2} \mathrm{O}\right)_{0.7}\right)_{\mathrm{n}}: \mathrm{C}, 62.15 ; \mathrm{H}, 4.31 ; \mathrm{N}, 24.16$. Found: $\mathrm{C}, 62.47 ; \mathrm{H}, 4.17$; $\mathrm{N}, 23.14$. Using $\mathbf{1} \cdot \mathbf{C l}(296 \mathrm{mg})$ and lithium perchlorate $\left(\mathrm{LiClO}_{4}\right)$ as starting materials, $\mathbf{1} \cdot \mathrm{ClO}_{4}$ was obtained as a white powder $(352 \mathrm{mg}, 94 \%) ;{ }^{1} \mathrm{H}$ NMR $\left(400 \mathrm{MHz}\right.$, DMSO- $\left.d_{6}\right) \delta 11.66(\mathrm{NH}, 1 \mathrm{H}), 8.96(2 \mathrm{H}), 8.34(2 \mathrm{H}), 8.08(2 \mathrm{H}), 7.67$ $(2 \mathrm{H}), 5.84\left(\mathrm{CH}_{2}, 2 \mathrm{H}\right),{ }^{13} \mathrm{C}$ NMR $\left(100 \mathrm{MHz}\right.$, DMSO- $\left.d_{6}\right) \delta 167.0,152.9,145.7$, $139.8,133.7,129.4,128.9,116.4$, 61.5. Anal calcd for $\left(\mathrm{C}_{13} \mathrm{H}_{11} \mathrm{ClN}_{2} \mathrm{O}_{5}\right.$ $\left.\left(\mathrm{H}_{2} \mathrm{O}\right)_{0.7}\right)_{\mathrm{n}}: \mathrm{C}, 48.30 ; \mathrm{H}, 3.87 ; \mathrm{N}, 8.66$. Found: $\mathrm{C}, 48.65 ; \mathrm{H}, 3.85 ; \mathrm{N}, 8.44$. Using $1 \cdot \mathrm{Cl}(382 \mathrm{mg})$ and lithium trifluoromethanesulfonate $\left(\mathrm{LiSO}_{3} \mathrm{CF}_{3}\right)$ as starting materials, $\mathbf{1} \cdot \mathrm{SO}_{3} \mathrm{CF}_{3}$ was obtained as a white powder $(525 \mathrm{mg}, 94 \%)$; 
${ }^{1} \mathrm{H}$ NMR $\left(400 \mathrm{MHz}\right.$, DMSO- $\left.d_{6}\right) \delta 11.66(\mathrm{NH}, 1 \mathrm{H}), 8.96(2 \mathrm{H}), 8.35(2 \mathrm{H}), 8.08$ $(2 \mathrm{H}), 7.68(2 \mathrm{H}), 5.84\left(\mathrm{CH}_{2}, 2 \mathrm{H}\right),{ }^{13} \mathrm{C}$ NMR $\left(100 \mathrm{MHz}, \mathrm{DMSO}-d_{6}\right) \delta 167.0$, $153.0,145.7,139.8,133.7,129.4,128.9,122.5,116.4,61.5 .{ }^{19} \mathrm{~F}$ NMR $(300 \mathrm{MHz}$, DMSO $\left.-d_{6}\right) \delta-77.3$.

\section{Preparation of gels}

A typical preparation method of gels was as follows: weighed amounts of gelator and solvent were sonicated in a screw-cap bottle for a short time using a cleaning bath to form a suspension. The suspension was then heated until a clear solution was formed. The solution was cooled at room temperature overnight, and the gelation was then checked visually by inverting the bottle. Regarding the units of concentration of the gels, 'wt\%' was used for the comparison between the conventional organic solvents. On the other hand, ' $\mathrm{gl}^{-1}$ ' was used for the ionic liquids with or without electrolyte additives because their density data to calculate 'wt $\%$ ' were not always available.

\section{Ionic conductivity measurements}

The ionic conductivity $(\sigma)$ of the ionogels was measured by a conductivity meter (Radiometer Analytical, Lyon, France, CDM-230) in a sealed conductivity cell (Radiometer Analytical, CDC-749) at an appropriate temperature controlled by an incubator. Ionogels were typically prepared with a gelator by heating, and then allowed to stand at room temperature. A conductivity cell was set into the initial hot solution of an ionic liquid containing the gelator before solidification, and the entire system was then cooled at room temperature to form an ionogel.

\section{RESULTS AND DISCUSSION}

Syntheses of oligomeric electrolytes by the anion exchange reaction The anion exchange reaction of $\mathbf{1} \cdot \mathrm{Cl}\left(M_{\mathrm{w}}=2.80, \mathrm{PDI}=1.66\right.$, polystyrene standard $)^{31}$ was carried out by the addition of an excess of an appropriate salt in a hot aqueous solution of $\mathbf{1} \cdot \mathbf{C l}$ (Scheme 2). Ammonium hexafluorophosphate $\left(\mathrm{NH}_{4} \mathrm{PF}_{6}\right)$, ammonium tetrafluoroborate $\left(\mathrm{NH}_{4} \mathrm{BF}_{4}\right)$, ammonium iodide $\left(\mathrm{NH}_{4} \mathrm{I}\right)$, sodium thiocyanate, sodium dicyanoamide, sodium tetraphenylborate $\left(\mathrm{NaBPh}_{4}\right)$, lithium perchlorate $\left(\mathrm{LiClO}_{4}\right)$, LiTFSA or lithium trifluoromethanesulfonate $\left(\mathrm{LiSO}_{3} \mathrm{CF}_{3}\right)$ was used for the anion exchange reaction. After the anion exchange reaction, a white or yellowish (in the case of an iodide anion) precipitate was formed. After cooling to room temperature, the precipitate was filtered and dried in vacuo to obtain the corresponding oligomer with an exchanged anion. In each case, the conversion yield was fairly high, estimated by a mass balance between the reactant and the product. The thermal properties of the new oligomeric electrolytes were evaluated by TGA. All the compounds were thermally decomposed without melting under the heating condition with nitrogen gas atmosphere (see Supplementary Figure S1). The apparently high char yields $(18-40 \%)$ should reflect the oligomeric structure of the materials in contrast to the conventional imidazolium ionic liquids, which typically show low char yields $(<10 \%)$ after pyrolysis in TGA. ${ }^{34}$ The highest thermal stability was observed for the TGA profile of $1 \cdot \mathrm{SO}_{3} \mathrm{CF}_{3}$, in which the decomposition start temperature reached
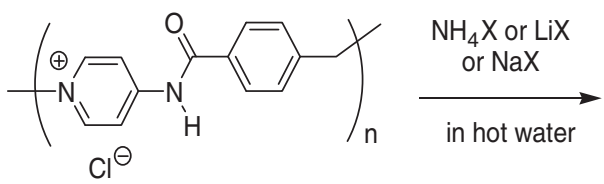

$1 \cdot \mathrm{Cl}$ approximately $350^{\circ} \mathrm{C}$. It is noteworthy that the preference of the $\mathrm{SO}_{3} \mathrm{CF}_{3}$ anion for the thermal property of the oligomeric electrolytes was also characteristic, in contrast to the common nature of the typical imidazolium ionic liquids. ${ }^{35}$

\section{Solubility and gelation ability of oligomeric electrolytes in organic} solvents

To examine the miscibility and gelation properties of the oligomeric electrolytes in various organic solvents, we referred to the categorization of solvents proposed by Kolthoff, ${ }^{36}$ which has been commonly used in the area of electrochemistry. According to the classification, general solvents are roughly divided into two main categories: amphiprotic and aprotic solvents. Amphiprotic solvents are subdivided into three categories, neutral, protogenic and protophilic solvents, on the basis of the strength of acidity and basicity compared with water in terms of the Brønsted concept. For aprotic solvents, there are also three subdivided categories, protophilic, protophobic and inert solvents, by the strength of basicity compared with water. Both amphiprotic and aprotic solvents are further divided by the strength of the dielectric factor $(\varepsilon)$. We tested 13 representative solvents, categorized as $1 \mathrm{a}, 4 \mathrm{a}, 4 \mathrm{~b}, 5 \mathrm{a}$ and $5 \mathrm{c}$ (water, methanol $(\mathrm{MeOH})$, ethanol (EtOH) (category 1a), dimethylsulfoxide (DMSO), dimethylformamide, dimethylacetamide (category 4a), dimethoxyethane, anisole (category 4b), acetone, acetonitrile, propylene carbonate (PC) (category 5a), chloroform and chlorobenzene (category 5c)) in Kolthoff's definition, to investigate the miscibility and gelation abilities of the oligomeric electrolytes for general solvents in organic chemistry and electrochemistry. The results are summarized in Table 1.

It was found that the anion exchange reaction dramatically changed the solubility of the oligomeric electrolyte. Although the oligomeric electrolyte $\mathbf{1} \cdot \mathbf{C l}$ is not soluble in any organic solvent, the products with an exchanged anion, such as $\mathrm{BF}_{4}, \mathrm{PF}_{6}$ and TFSA, dissolved well in several organic solvents. In the case of the solvents categorized as 1a, a translucent hydrogel was obtained using $\mathbf{1} \cdot \mathbf{B F} \mathbf{F}_{4}$ at $1 \mathrm{wt} \%$ concentration, whereas the other oligomers did not dissolve in water. The solubility of $\mathbf{1} \cdot \mathbf{B F}_{4}$ in water was much lower than that of $\mathbf{1} \cdot \mathbf{C l}$; thus, $1 \mathrm{wt} \%$ was the maximum concentration of $\mathbf{1} \cdot \mathbf{B F}_{4}$ even in hot water. $1 \cdot$ TFSA and $1 \cdot \mathrm{SO}_{3} \mathrm{CF}_{3}$ were not soluble in water, but sparsely soluble in $\mathrm{MeOH}$. Using 1.TFSA, a $\mathrm{MeOH}$ gel was available at $5 \mathrm{wt} \%$ concentration. The oligomers except for $\mathbf{1} \cdot \mathbf{C l}$ were miscible in the solvents categorized as 4a with moderate basicity and a high dielectric factor $(\varepsilon>20)$, such as dimethylformamide, DMSO and dimethylacetamide, while being insoluble in the solvents categorized as $4 \mathrm{~b}$, with a low dielectric factor $(\varepsilon<20)$. Therefore, the dielectric factor should strongly affect the miscibility of the oligomers, and the intrinsic solubility increased with an increase in the dielectric factor. In addition, organogels of the solvents in category $4 \mathrm{a}$ were obtained

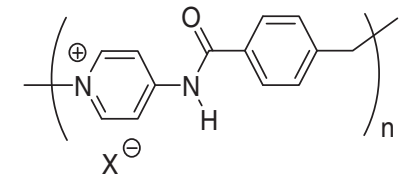

$$
\begin{aligned}
\mathrm{X}= & \mathrm{BF}_{4}, \mathrm{PF}_{6}, \mathrm{TFSA} \mathrm{BPh}_{4}, \mathrm{I}, \\
& \mathrm{SCN}, \mathrm{DCA}, \mathrm{ClO}_{4}, \mathrm{SO}_{3} \mathrm{CF}_{3} \\
& \text { 1. } \mathrm{BF}_{4}, 1 \cdot \mathrm{PF}_{6}, 1 \cdot \mathrm{TFSA}, 1 \cdot \mathrm{BPh}_{4}, 1 \cdot \mathrm{I}, \\
& \text { 1.SCN, 1.DCA, 1. } \mathrm{ClO}_{4}, \mathbf{1} \cdot \mathrm{SO}_{3} \mathrm{CF}_{3}
\end{aligned}
$$


Table 1 Solubility and gelation ability of oligomeric electrolytes $1 \cdot \mathbf{X}\left(\mathrm{X}\right.$ : anion) ${ }^{\mathrm{a}}$

\begin{tabular}{|c|c|c|c|c|c|c|c|c|c|c|}
\hline Solvent $(\varepsilon)^{\mathrm{b}}$ & $1 \cdot \mathrm{Cl}$ & $1 \cdot B F_{4}$ & $1 \cdot P F_{6}$ & $1 \cdot T F S A$ & $1 \cdot B P h_{4}$ & $1 \cdot 1$ & $1 \cdot S C N$ & $1 \cdot D C A$ & $1 \cdot \mathrm{ClO}_{4}$ & $1 \cdot \mathrm{SO}_{3} \mathrm{CF}_{3}$ \\
\hline \multicolumn{11}{|l|}{ 1a } \\
\hline $\mathrm{H}_{2} \mathrm{O}$ (78.4) & $\mathrm{G}$ & $\mathrm{G}$ & I & I & 1 & $\mathrm{P}$ & $P G$ & $P$ & 1 & I \\
\hline \multirow[t]{2}{*}{$\mathrm{MeOH}(32.7)$} & 1 & 1 & 1 & $\mathrm{~S}$ & I & 1 & 1 & 1 & 1 & $S$ \\
\hline & - & - & - & G & - & - & - & - & - & $P$ \\
\hline EtOH (24.6) & 1 & 1 & 1 & I & 1 & 1 & 1 & 1 & 1 & 1 \\
\hline \multicolumn{11}{|l|}{$4 a$} \\
\hline \multirow[t]{2}{*}{ DMF (36.7) } & 1 & $S$ & S & S & S & G (0.5) & S & $S$ & S & $S$ \\
\hline & - & G & s & s & s & $\mathrm{G}^{\mathrm{c}}$ & G (2) & $P G$ & G & $P G$ \\
\hline \multirow[t]{2}{*}{ DMSO (46.5) } & 1 & S & S & S & $\mathrm{s}$ & S & s & $\mathrm{s}$ & S & $\mathrm{S}$ \\
\hline & - & s & s & s & $P G$ & G (2) & $P G$ & s & s & s \\
\hline DMA (37.8) & I & S & S & S & $\mathrm{S}$ & G & $\mathrm{s}$ & I & S & S \\
\hline DME (7.20) & - & - & - & - & - & - & - & - & - & - \\
\hline \multirow[t]{2}{*}{ Anisole (4.33) } & 1 & 1 & 1 & I & 1 & 1 & 1 & 1 & 1 & I \\
\hline & - & - & - & - & - & - & - & - & - & - \\
\hline \multicolumn{11}{|l|}{$5 a$} \\
\hline \multirow[t]{2}{*}{ Acetone (20.6) } & 1 & 1 & 1 & $P$ & 1 & 1 & 1 & 1 & 1 & 1 \\
\hline & - & - & - & - & - & - & - & - & - & - \\
\hline \multirow[t]{2}{*}{ AN (35.9) } & । & $\mathrm{P}$ & $\mathrm{s}$ & $\mathrm{s}$ & S & 1 & । & 1 & 1 & I \\
\hline & - & - & S & S & $P$ & - & - & - & - & - \\
\hline \multirow[t]{2}{*}{ PC (64.9) } & I & $\mathrm{s}$ & s & $\mathrm{s}$ & s & 1 & 1 & $P G$ & $\mathrm{~s}$ & S \\
\hline & - & S & S & S & S & - & - & G (1.5) & $P G$ & $P G$ \\
\hline \multicolumn{11}{|l|}{$5 c$} \\
\hline
\end{tabular}

Abbreviations: AN, acetonitrile; $\mathrm{Cl}-\mathrm{Bz}$, chlorobenzene; DMA, dimethylacetamide; DME, dimethoxyethane; DMF, dimethylformamide; DMSO, dimethylsulfoxide; EtOH, ethanol; G, gel; I, insoluble; $\mathrm{MeOH}$, methanol; P, precipitate; PC, propylene carbonate; PG, partial gel; S, solution.

aThe concentration of each oligomeric electrolyte was 1 wt\% (above) and 5 wt $\%$ (below). First, we tried to test the solubility at 1 wt\% concentration; next, when dissolved, the solubility was investigated at 5 wt\% concentration. The number in parentheses indicates the minimum gel concentration.

bielectric factor of the solvent.

${ }^{\mathrm{c}}$ The gel became heterogeneous due to the precipitation of the gelator compound.

with $\mathbf{1} \cdot \mathrm{I}$ and $\mathbf{1} \cdot \mathrm{SCN}$ at $0.5-2 \mathrm{wt} \%$ concentrations. The use of $\mathbf{1} \cdot \mathrm{ClO}_{4}$ and $\mathbf{1} \cdot \mathbf{S O}_{3} \mathbf{C F}_{3}$ also resulted in organogels at higher concentrations ( $5 \mathrm{wt} \%)$. The solvents categorized as $5 \mathrm{a}$ have a high dielectric factor $(\varepsilon>20)$, as do the category-4a solvents, but have a lower basicity than that of water. Despite the high dielectric factor of the solvents of $5 \mathrm{a}$, the oligomers $\mathbf{1} \cdot \mathbf{C l}, \mathbf{1} \cdot \mathbf{I}$ and $\mathbf{1} \cdot \mathbf{S C N}$ were insoluble even in PC. In contrast, the oligomeric electrolytes $\mathbf{1} \cdot \mathbf{P F}_{6}, \mathbf{1} \cdot \mathbf{T F S A}$ and $\mathbf{1} \cdot \mathbf{B} \mathbf{P h}_{4}$ show good solubility in the solvents of $5 \mathrm{a}$, except for acetone. PC is the best solvent to dissolve these oligomeric electrolytes, and a PC gel was obtained using an oligomer 1.DCA at $1.5 \mathrm{wt} \%$ concentration. In the solvents categorized as $5 c$, chloroform and chlorobenzene, all the oligomers were insoluble.

\section{Preparation of ionic liquid gels (ionogels)}

Previously, we preliminarily reported that the oligomeric electrolyte $\mathbf{1} \cdot \mathbf{P F}_{6}$ gelatinized several ionic liquids, that is, 1-ethyl-1-methyl-

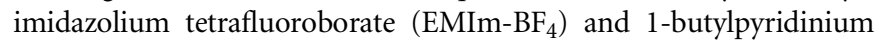

tetrafluoroborate $\left(1-\mathrm{BuPy}_{\mathrm{B}} \mathrm{BF}_{4}\right) .{ }^{31}$ As depicted in Figure 1 and Table 2, we further investigated the gelation abilities of oligomeric electrolytes $1 \cdot \mathrm{PF}_{6}, 1 \cdot \mathrm{BF}_{4}$ and 1.TFSA for several ionic liquids on the basis of the imidazolium and tetraalkylammonium structures, which are expected to be useful for electronic devices because of high ionic conductivities and

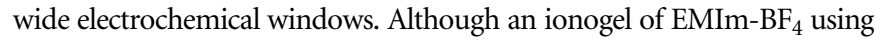
$\mathbf{1} \cdot \mathrm{PF}_{6}$ was obtained at the minimum concentration of $12 \mathrm{gl}^{-1}$, it was difficult to obtain ionogels on the basis of imidazolium ionic liquids with a longer alkyl chain or the TFSA anion, that is, 1-butyl-3-methylimida-

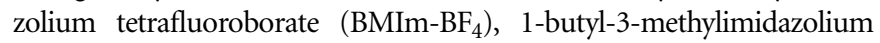
hexafluorophosphate $\left(\mathrm{BMIm}^{-} \mathrm{PF}_{6}\right)$, 1-hexyl-3-methylimidazolium tetrafluoroborate $\left(\mathrm{HMIm}-\mathrm{BF}_{4}\right)$ and 1-ethyl-3-methyl imidazolium bis(trifluoromethanesulfonyl)amide (EMIm-TFSA), by oligomeric electrolytes $\mathbf{1} \cdot \mathrm{PF}_{6}, \mathbf{1} \cdot \mathrm{BF}_{4}$ and $\mathbf{1} \cdot \mathrm{TFSA}$. It was therefore presumed that the size of cationic moieties or the hydrophobicity of ionic liquids was very important to match the miscibility and gelation property of the oligomeric electrolytes. 
<smiles>CC[n+]1ccn(C)c1</smiles>

$\mathrm{EMIm}^{-\mathrm{BF}_{4}}$<smiles>CCCC[n+]1ccn(C)c1</smiles>

BMIm-BF 4<smiles>CCC[N+]1(C)CCCCC1</smiles><smiles>O=S(=O)(NS(=O)(=O)C(F)(F)F)C(F)(F)F</smiles>

PP13-TFSA

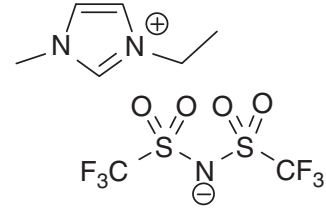

EMIm-TFSA<smiles>CCCC[n+]1ccn(C)c1</smiles>

BMIm-PF 6

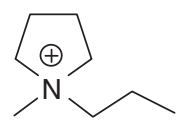<smiles>O=S(=O)(NS(=O)(=O)C(F)(F)F)C(F)(F)F</smiles>

PY13-TFSA
Figure 1 Chemical structures of typical ionic liquids.

Table 2 Gelation ability of $1 \cdot \mathrm{PF}_{6}, 1 \cdot \mathrm{BF}_{4}$ and $1 \cdot \mathrm{TFSA}$ in several ionic liquids ${ }^{a}$

\begin{tabular}{|c|c|c|c|}
\hline Ionic liquids & $1 \cdot P F_{6}$ & $1 \cdot B F_{4}$ & $1 \cdot$ TFSA \\
\hline $\mathrm{EMIm}-\mathrm{BF}_{4}$ & G (12) & $P G$ & $P$ \\
\hline EMIm-TFSA & $\mathrm{P}$ & $P$ & $P$ \\
\hline $\mathrm{BMIm}-\mathrm{BF}_{4}$ & $P$ & $P$ & $\mathrm{P}$ \\
\hline $\mathrm{BMIm}-\mathrm{PF}_{6}$ & $\mathrm{P}$ & $\mathrm{P}$ & - \\
\hline PP13-TFSA & - & - & G (40) \\
\hline PY13-TFSA & - & - & G (40) \\
\hline
\end{tabular}

Abbreviations: G, gel; P, precipitate; PG, partial gel.

aThe general concentration of each oligomeric electrolyte was $20 \mathrm{gl}^{-1}$. The number in parentheses indicates the minimum gel concentration $\left(\mathrm{gl}^{-1}\right)$.

We tried to prepare the dried gel (xerogel) of an ionogel to examine the morphology of the assembled gelator molecules in an ionic liquid. Although the freeze-dry method for preparation of xerogels is generally used, it is very difficult for an ionic liquid to be evaporated by continuous vacuum pumping. Therefore, we obtained dried ionogel after a thorough rinsing of the ionogel based on EMIm- $\mathrm{BF}_{4}$ with $\mathbf{1} \cdot \mathbf{P F}_{\mathbf{6}}$ by water to remove the ionic liquid, followed by drying in vacuo. As shown in Figure 2, the multilayer film structure was observed in the field-emission scanning electron microscope measurement to be similar to the morphology of a xerogel prepared from a hydrogel based on $\mathbf{1} \cdot \mathbf{C l}$. $^{31}$ It is presumed that the liquid medium would be trapped between the layers to be gelatinized, although the multilayer structure is different from that of the known ionogels based on the low-molecular-weight gelators with a three-dimensional fibrous network. ${ }^{21}$ As discussed in the previous section, the solubility of oligomeric electrolytes 1.TFSA in organic solvents is slightly better than that of $\mathbf{1} \cdot \mathbf{P F}_{\mathbf{6}}$. Indeed, the oligomeric electrolyte $\mathbf{1} \cdot \mathbf{T F S A}$ was well soluble in several imidazolium-type ionic liquids at a high temperature: EMIm-BF 4 , EMIm-TFSA and BMIm- $\mathrm{PF}_{6}$. Precipitates of

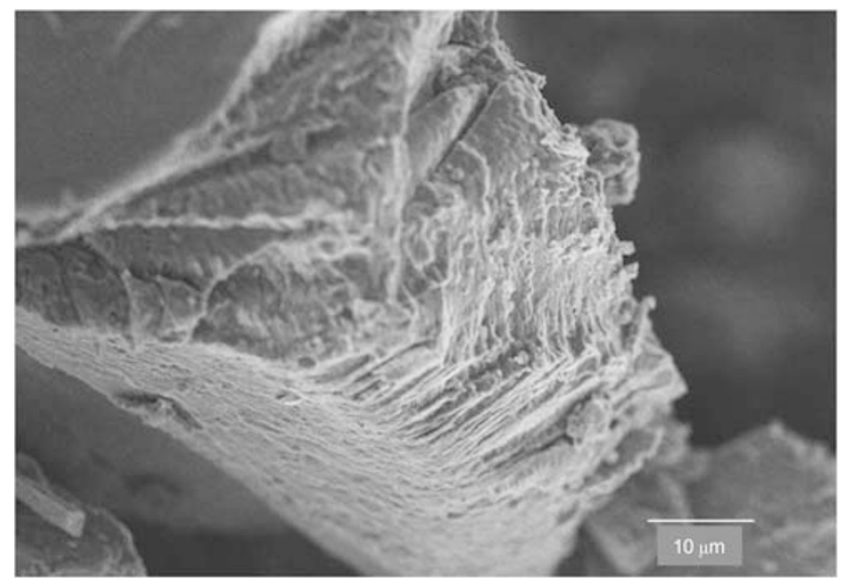

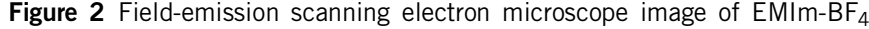
xerogel formed by $1 \cdot \mathrm{PF}_{6}$.

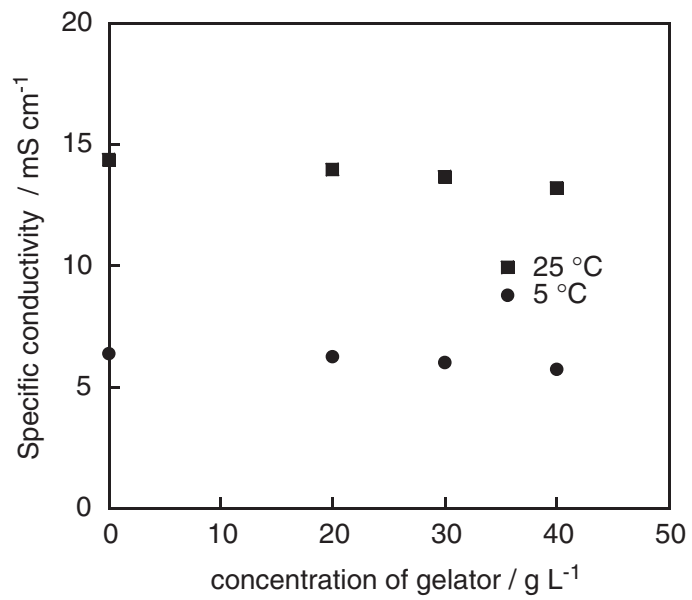

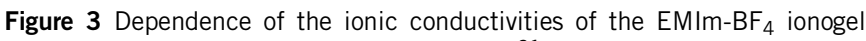
on the concentration of $\mathbf{1} \cdot \mathrm{PF}_{6}$ at 5 and $25^{\circ} \mathrm{C} .{ }^{31}$

1.TFSA, however, were formed in these ionic liquids on cooling. On the other hand, several tetraalkylammonium-type ionic liquids, for example, $N$-methyl- $N$-propylpiperidinium bis(trifluoromethanesulfonyl)amide (PP13-TFSA) and $N$-methyl- $N$-propylpyrrolidinium bis(trifluoromethanesulfonyl)amide (PY13-TFSA), were gelatinized using 1.TFSA at $40 \mathrm{gl}^{-1}$ concentration. These aliphatic ionic liquids are expected to be useful as the electrolyte for a Li-ion secondary battery because of a wide electrochemical window and the relatively high ionic conductivity among the ammonium-type ionic liquids. ${ }^{37}$

\section{Ionic conductivities of ionogels}

Although one of the most important features of ionic liquids is the high ionic conductivity with respect to the application as a novel organic electrolyte, solid or quasi-solid electrolytes are often preferable in practical uses to prevent electrolyte leakage. If the gelation does not change the intrinsic ionic conductivity of the ionic liquid, the procedure may become a convenient method to obtain quasi-solid electrolytes with high conductivity. However, a decrease in ionic conductivity after gelation of ionic liquids was often observed. ${ }^{19-23}$ We initially reported the ionic conductivities of the EMIm-BF 4 gel formed by the oligomeric gelator $\mathbf{1} \cdot \mathbf{P F}_{6}$ at $0-40 \mathrm{gl}^{-1}$ concentrations at 5 and $25^{\circ} \mathrm{C} .{ }^{31}$ Although the ionic conductivity slightly decreased with 


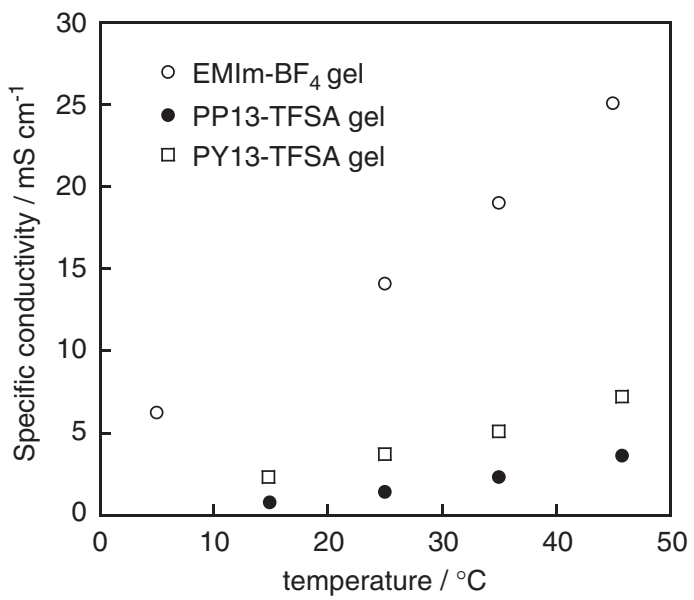

Figure 4 Temperature dependency of the ionic conductivities of ionogels: EMIm-BF 4 gel with 1.PF, PP13-TFSA gel with 1-TFSA and PY13-TFSA with 1.TFSA.

Table 3 Comparison of ionic conductivity of ionic liquids and the corresponding gels at room temperature $\left(25^{\circ} \mathrm{C}\right)^{\mathrm{a}}$

\begin{tabular}{|c|c|c|c|c|c|}
\hline Ionic liquid & Gelator & $\begin{array}{c}\text { Temperature } \\
\left({ }^{\circ} \mathrm{C}\right)\end{array}$ & $\begin{array}{c}\sigma_{l} \\
\left(m S c m^{-1}\right)\end{array}$ & $\sigma_{g}\left(m S c m^{-1}\right)$ & $\sigma_{g} / \sigma_{l}$ \\
\hline \multirow[t]{3}{*}{$\mathrm{EMIm}^{-\mathrm{BF}_{4}}$} & $1 \cdot \mathrm{PF}_{6}{ }^{\mathrm{b}}$ & 25 & 14.4 & 14.1 & 0.98 \\
\hline & & 35 & 19.7 & 19.0 & 0.96 \\
\hline & & 45 & 25.9 & 25.1 & 0.97 \\
\hline \multirow[t]{5}{*}{ PP13-TFSA } & $1 \cdot \mathrm{TFSA}^{\mathrm{C}}$ & 15 & 0.85 & 0.77 & 0.91 \\
\hline & & 25 & 1.6 & 1.4 & 0.88 \\
\hline & & 35 & 2.6 & 2.3 & 0.88 \\
\hline & & 45 & 3.8 & 3.6 & 0.95 \\
\hline & & 55 & 5.3 & 5.0 & 0.94 \\
\hline \multirow[t]{5}{*}{ PY13-TFSA } & 1.TFSA ${ }^{\mathrm{C}}$ & 15 & 2.5 & 2.3 & 0.92 \\
\hline & & 25 & 3.8 & 3.7 & 0.97 \\
\hline & & 35 & 5.7 & 5.1 & 0.89 \\
\hline & & 45 & 7.6 & 7.2 & 0.95 \\
\hline & & 55 & 9.8 & 9.3 & 0.95 \\
\hline PP13-TFSA+ & 1. TFSA $^{\mathrm{C}}$ & 15 & 0.38 & 0.33 & 0.89 \\
\hline \multirow[t]{4}{*}{ 10\% LiTFSA } & & 25 & 0.75 & 0.66 & 0.88 \\
\hline & & 35 & 1.4 & 1.2 & 0.86 \\
\hline & & 45 & 2.3 & 2.0 & 0.87 \\
\hline & & 55 & 3.4 & 3.0 & 0.88 \\
\hline
\end{tabular}

${ }^{\mathrm{a}} \sigma_{1}$, conductivity of ionic liquids, $\sigma_{\mathrm{g}}$, conductivity of ionogels.

bThe concentration of gelator $1 \cdot \mathrm{PF}_{6}$ was $20 \mathrm{gl}^{-1}$

CThe concentration of gelator 1.TFSA was $40 \mathrm{gl}^{-1}$.

increasing amounts of the gelator, the conductivities were almost identical to the intrinsic conductivity of the ionic liquid at each temperature, as shown in Figure 3. The temperature dependencies of the ionic conductivities of the ionogels, namely, the EMIm- $\mathrm{BF}_{4}$ gel with $\mathbf{1} \cdot \mathrm{PF}_{\mathbf{6}}$ at $20 \mathrm{gl}^{-1}$ concentration, PP13-TFSA and PY13-TFSA gels with 1.TFSA at $40 \mathrm{gl}^{-1}$ concentration, are described in Figure 4 . The ionic conductivity increased with increasing temperature, as with neat ionic liquids, without any apparent change due to the quasi-solid nature. Compared with the ionic conductivities of ionic liquids before and after gelation, it was found that the ionic conductivities were well maintained in a wide range of temperatures in the gel state (Table 3). Although the slight decrease in ionic conductivities is mostly consistent with the observation in the previous study, ${ }^{21}$ the conductivities

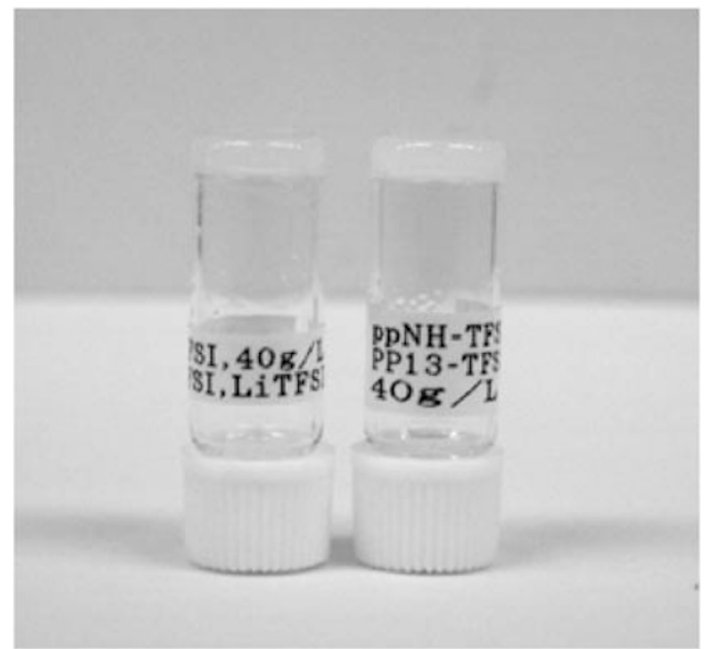

Figure 5 lonogel of PP13-TFSA with 1.TFSA at $40 \mathrm{gl}^{-1}$ concentration (right) and ionogel of PP13-TFSA $+10 \%$ LiTFSA with 1.TFSA at $40 \mathrm{gl}^{-1}$ concentration (left) in upturned vials.

observed $\left(\sigma \sim 10^{-2}-10^{-3} \mathrm{~S} \mathrm{~cm}^{-1}\right)$ in this study are higher than those

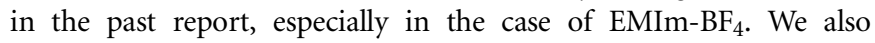
confirmed that the activation energy $\left(E_{\mathrm{a}}\right)$ of the ionic conductivity estimated by an Arrhenius plot did not change after gelation $\left(E_{\mathrm{a}}=11\right.$, $15,11 \mathrm{~kJ} \mathrm{~mol}^{-1}$ for EMIm-BF 4 , PP13-TFSA and PY13-TFSA, respectively). Regarding the application for electronic devices, a supporting electrolyte has often been added to the ionic liquids. It is thus worth noting that the oligomeric electrolyte 1-TFSA gelatinized the mixed solution of an ionic liquid PP13-TFSA, containing $10 \mathrm{wt} \%$ concentration of a supporting electrolyte LiTFSA, at the same concentration $\left(40 \mathrm{gl}^{-1}\right)$ as the original gelation condition without the lithium salt (Figure 5). The ionic conductivity of the ionogel of PP13-TFSA with a LiTFSA salt was maintained at the $86-89 \%$ level of the intrinsic values even after gelation, as shown in Table 3.

\section{CONCLUSIONS}

The following nine oligomeric electrolytes, $\mathbf{1} \cdot \mathrm{BF}_{4}, \mathbf{1} \cdot \mathrm{PF}_{\mathbf{6}}, \mathbf{1} \cdot \mathrm{TFSA}$, $1 \cdot \mathrm{BPh}_{4} 1 \cdot \mathrm{I}, 1 \cdot \mathrm{SCN}, 1 \cdot \mathrm{DCA}, \mathbf{1} \cdot \mathrm{ClO}_{4}$ and $1 \cdot \mathrm{SO}_{3} \mathrm{CF}_{3}$, were prepared by the facile anion exchange reaction using $\mathbf{1} \cdot \mathbf{C l}$ (poly[pyridinium-1,4diyl-iminocarbonyl-1,4-pheylene-methylene chloride]) as a starting material. Eventually, we succeeded in tuning the solubility of the oligomeric electrolytes for organic solvents by the anion exchange method from chloride into hydrophobic ones. Several organic solvents with a high dielectric factor, such as dimethylformamide, DMSO, dimethylacetamide and PC, showed excellent miscibility with the oligomers. In addition to organic solvents, several ionic liquids were gelatinized by these oligomeric electrolytes. The ionic conductivities of the ionogels were adequately maintained in comparison with the intrinsic one of neat ionic liquids. The gelator 1.TFSA also gelatinized an ionic liquid containing lithium salt as a supporting electrolyte. These gelators have the potential to provide gel electrolytes for various electronic devices, such as Li-ion batteries, dye-sensitized solar cells and electric double-layer capacitors.

TGA curves of the oligomeric electrolytes with different anions. This material is available free of charge via the Polymer Journal website.

\section{ACKNOWLEDGEMENTS}

This work was supported by the Industrial Technology Research Grant Program (05A25710a) from the New Energy and Industrial Technology Development 
Organization (NEDO) of Japan. We thank Dr Junji Mizukado for the ${ }^{19} \mathrm{~F}$ NMR measurements.

1 Guenet, J. M. Thermoreversible Gelation of Polymers and Biopolymers, Academic Press: London, 1992

2 Osada, Y., Gong, J. P. \& Tanaka, Y. Polymer Gels. Polymer Rev 44, 87 (2004).

3 van den Berg, A. M. J., de Laat, A. W. M., Smith, P. J., Perelaer, J. \& Schubert, U. S. Geometric control of inkjet printed features using a gelating polymer. J. Mater. Chem. 17, 677 (2007)

4 van Esch, J. H. \& Feringa, B. L. New functional materials based on self-assembling organogels: from serendipity towards design. Angew. Chem. Int. Ed. 39, 2263 (2000).

5 Abdallah, D. J. \& Weiss, R. G. Organogels and low molecular mass organic gelators. Adv. Mater. 12, 1237 (2000).

6 Terech, P. \& Weiss, R. G. Low molecular mass gelators of organic liquids and the properties of their gels. Chem. Rev. 97, 3133 (1997).

7 Gronwald, O., Snip, E. \& Shinkai, S. Gelators for organic liquids based on selfassembly: a new facet of supramolecular and combinatorial chemistry. Curr. Opin. Colloid Interface Sci. 7, 148 (2002).

8 Murata, K., Aoki, M., Suzuki, T., Harada, T., Kawabata, H., Komori, T., Ohseto, F., Ueda, K. \& Shinkai, S. Thermal and light control of the sol-gel phase transition in cholesterol-based organic gels. Novel helical aggregation modes as detected by circular dichroism and electron microscopic observation. J. Am. Chem. Soc. 116, 6664 (1994).

9 Moriyama, M., Mizoshita, N., Yokota, T., Kishimoto, K. \& Kato, T. Photoresponsive anisotropic soft solids: liquid-crystalline physical gels based on a chiral photochromic gelator. Adv. Mater. 15, 1335 (2003).

10 de Jong, J. J. D., Lucas, L. N., Kellogg, R. M., van Esch, J. H. \& Feringa, B. L. Reversible optical transcription of supramolecular chirality into molecular chirality. Science 304, 278 (2004).

11 Matsuzawa, Y., Ueki, K., Yoshida, M., Tamaoki, N., Nakamura, T., Sakai, H. \& Abe, M. Assembly and photoinduced organization of mono- and oligopeptide molecules containing an azobenzene moiety. Adv. Funct. Mater. 17, 1507 (2007).

12 Haines, S. R. \& Harrison, R. G. Novel resorcinarene-based pH-triggered gelator. Chem. Commun. 2846 (2002).

13 George, M. \& Weiss, R. G. Chemically reversible organogels via 'latent' gelators. Aliphatic amines with carbon dioxide and their ammonium carbamates. Langmuir 18, 7124 (2002).

14 Lyon, R. P. \& Atkins, W. M. Self-assembly and gelation of oxidized glutathione in organic solvents. J. Am. Chem. Soc. 123, 4408 (2001).

15 Holbrey, D. \& Seddon, K. R. Ionic Liquids. Clean Prod. Process 1, 223 (1999).

16 Welton, T. Room-temperature ionic liquids. solvents for synthesis and catalysis. Chem. Rev. 99, 2071 (1999).

17 Dupont, J., de Souza, R. F. \& Suarez, P. A. Z. Ionic liquid (molten salt) phase organometallic catalysis. Chem. Rev. 102, 3667 (2002).

18 Zhou, Z.- B., Matsumoto, H. \& Tatsumi, K. Low-melting, low-viscous, hydrophobic ionic liquids: aliphatic quaternary ammonium salts with perfluoroalkyltrifluoroborates. Chem. Eur. J. 11, 752 (2005).
19 Ikeda, A., Sonoda, K., Ayabe, M., Tamaru, S., Nakashima, T., Kimizuka, N. \& Shinkai, S. Gelation of ionic liquids with a low molecular-weight gelator showing $T_{\text {gel }}$ above $100{ }^{\circ} \mathrm{C}$. Chem. Lett. 11, 1154-1155 (2001).

20 Kimizuka, N. \& Nakashima, T. Spontaneous self-assembly of glycolipid bilayer membranes in sugar-philic ionic liquids and formation of ionogels. Langmuir 17, 6759 (2001).

21 Hanabusa, K., Fukui, H., Suzuki, M. \& Shirai, H. Specialist gelator for ionic liquids. Langmuir 21, 10383 (2005).

22 Susan, M. A., Kaneko, T., Noda, A. \& Watanabe, M. Ion gels prepared by in situ radical polymerization of vinyl monomers in an ionic liquid and their characterization as polymer electrolytes. J. Am. Chem. Soc. 127, 4976 (2005).

23 Noro, A., Matsushita, Y. \& Lodge, T. P. Thermoreversible supramacromolecular ion gels via hydrogen bonding. Macromolecules 41, 5839 (2008).

24 Mohmeyer, N., Kuang, D., Wang, P., Schmidt, H.- W., Zakeeruddin, S. M. \& Grätzel, M. An efficient organogelator for ionic liquids to prepare stable quasi-solid-state dyesensitized solar cells. J. Mater. Chem. 16, 2978 (2006).

25 Wang, P., Zakkeruddin, S., Comte, P., Exnar, I. \& Grätzel, M. Gelation of ionic liquidbased electrolytes with silica nanoparticles for quasi-solid-state dye-sensitized solar cells. J. Am. Chem. Soc. 125, 1166 (2003).

26 Kubo, W., Kambe, S., Nakade, S., Kitamura, T., Hanabusa, K., Wada, Y. \& Yanagida, S. Photocurrent-determining processes in quasi-solid-state dye-sensitized solar cells using ionic gel electrolytes. J. Phys. Chem. B 107, 4374 (2003).

27 Kubo, W., Kitamura, T., Hanabusa, K., Wada, Y. \& Yanagida, S. Quasi-solid-state dyesensitized solar cells using room temperature molten salts and a low molecular weight gelator. Chem. Commun. 374-375 (2002).

28 Jung, J. H., Rim, J. A., Han, W. S., Lee, J. S., Cho, J. E., Kim, J. S., Ji, Q. \& Shimizu, T. Hydrogel behavior of a sugar-based gelator by introduction of an unsaturated moiety as a hydrophobic group. Org. Biomol. Chem. 4, 2033 (2006).

29 Jung, J. H., Shinkai, S. \& Shimizu, T. Spectral characterization of self-assemblies of aldopyranoside amphiphilic gelators: What is the essential structural difference between simple amphiphiles and bolaamphiphiles? Chem. Eur. J. 8, 2684 (2002).

30 Suzuki, M., Owa, S., Kimura, M., Kurose, A., Shirai, H. \& Hanabusa, K. Supramolecular hydrogels and organogels based on novel L-valine and L-isoleucine amphiphiles. Tetrahedron Lett. 46, 303 (2005).

31 Yoshida, M., Koumura, N., Misawa, Y., Tamaoki, N., Matsumoto, H., Kawanami, H., Kazaoui, S. \& Minami, N. Oligomeric electrolyte as a multi-functional gelator. J. Am. Chem. Soc. 129, 11039 (2007).

32 Kundu, S. K., Matsunaga, T., Yoshida, M. \& Shibayama, M. Rheological study on rapid recovery of hydrogel based on oligomeric electrolyte. J. Phys. Chem. B. 112, 11537 (2008).

33 Kundu, S. K., Yoshida, M. \& Shibayama, M. Effect of salt content on the rheological properties of hydrogel based on oligomeric electrolyte. J. Phys. Chem. B. 114, 1541 (2010).

34 Kosmulski, M., Gustafsson, J. \& Rosenholm, J. B. Thermal stability of low temperature ionic liquids revisited. Thermochimica Acta 412, 47 (2004).

35 Ngo, H. L., LeCompte, K., Hargens, L. \& McEwen, A. B. Thermal properties of imidazolium ionic liquids. Thermochimica Acta 357-358, 97 (2000).

36 Kolthoff, I. M. Acid-base equilibriums in dipolar aprotic solvents. Anal. Chem. 46, 1992 (1974).

37 Sakaibe, H. \& Matsumoto, H. N-Methyl- $N$-propylpiperidinium bis(trifluoromethanesulfonyl)imide (PP13-TFSI) - novel electrolyte base for Li battery. Electrochem. Commun. 5, 594 (2003)

Supplementary Information accompanies the paper on Polymer Journal website (http://www.nature.com/pj) 